\title{
La generación del movimiento estudiantil en Colombia. 1910-1924 ${ }^{1}$
}

\author{
The generation of the student movement in Colombia. 1910-1924
}

A geração do movimento estudantil na Colômbia. 1910-1924

\author{
Diana Elvira Soto Arango ${ }^{2}$ \\ Universidad Pedagógica y Tecnológica de Colombia (Colombia) \\ Grupo Investigación HISULA - UPTC \\ José Antonio Rivadeneira ${ }^{3}$ \\ Academia Colombiana de Historia (Colombia) \\ Jorge Enrique Duarte Acero ${ }^{4}$; Sandra Liliana Bernal Villate ${ }^{5}$ \\ Universidad Pedagógica y Tecnológica de Colombia (Colombia) \\ Grupo Investigación HISULA - UPTC
}

Recepción: 20/05/2017

Evaluación: 08/06/2017

Aceptación: 05/01/2018

Artículo de investigación - Reflexión

DOI: https://doi.org/10.19053/01227238.8056

1 Resultado del proyecto de investigación "La Universidad Pedagógica y Tecnológica de Colombia en los desafíos del siglo XXI. Una prospectiva desde los estudiantes y docentes". Código: SGI 1965 financiado por la vicerrectoría de Investigaciones - UPTC y desarrollado por el Grupo de Investigación "Historia y Prospectiva de la Universidad Latinoamericana". HISULA.

2 Doctora en Filosofía y Ciencias de la Educación UNED, España, Postdoctorado Consejo Superior de Investigaciones CientíficasCSIC. Profesora UPTC. Investigadora y profesora del Doctorado en Ciencias de la Educación RUDECOLOMBIA. Directora Grupos de Investigación HISULA e ILAC (Categoría A COLCIENCIAS). ORCID: 0000-0002-3821-7550. Correo electrónico: diana.soto@ uptc.edu.co

3 Licenciado en Derecho por la Universidad Externado de Colombia. Expresidente de la Federación Internacional de Sociedades Bolivarianas y de la Sociedad Latinoamericana de Estudios sobre América Latina (SOLAR), fue fundador del Instituto de Estudios para el Desarrollo y la Integración de América Latina (IDESIL) y director del Instituto Colombiano de Estudios Latinoamericanos y del Caribe (ICELAC).

4 Doctor en Ciencias de la Educación-RUDECOLOMBIA. Profesor UPTC, director Maestría Gerencia Educacional. Integrante del Grupo de Investigación Historia y Prospectiva de la Universidad Latinoamericana- HISULA. Categoría A. Colciencias. Miembro de SHELA. Sociedad de Historia de la Educación Latinoamericana. Correo electrónico: Jorge.duarte@uptc.edu.co

5 Magíster en Historia de América de la Universidad Pablo de Olavide - Sevilla - España, Doctoranda del programa Historia y Estudios Humanísticos: Europa, América, Arte y Lenguas de la Universidad Pablo de Olavide. Actualmente es docente de la Universidad Pedagógica y Tecnológica de Colombia, adscrita a la Licenciatura en Ciencias Sociales, integrante del grupo de HISULA - UPTC, asistente editorial de RHELA. Correo electrónico: sandra.bernal@uptc.edu.co 


\section{RESUMEN}

El objeto de este trabajo se enfoca en el análisis de dos líderes estudiantiles agrupados en la generación del centenario y en la de los nuevos. A quienes vivieron el periodo del centenario de la independencia americana, también les correspondió la época del movimiento estudiantil colombiano junto con los nuevos y fueron marcados por el movimiento estudiantil de Córdoba en esta región latinoamericana. Entre otros, nos referimos a Luis López de Mesa (1884-1967), generación del centenario y Germán Arciniegas (1900-1999), generación de los nuevos. El periodo histórico de estudio abarca de 1910 a 1924 cuando tuvieron lugar el primer y segundo Congreso estudiantil colombiano. Desde la historia política analizamos a los líderes estudiantiles que luego ocuparon el Ministerio de Educación, bajo gobiernos liberales. Ambos, se caracterizaron por la docencia universitaria, sus aportes al periodismo y por generar planteamientos de reforma a la universidad colombiana. Estudiamos también su concepción sobre la educación, la universidad y sus propuestas universitarias desde la mirada de los movimientos estudiantiles y en especial la influencia del Movimiento de Córdoba en Colombia. La metodología comparada se sustenta principalmente en fuentes primarias. Nuestro estudio logra concluir que a pesar que alcanzar cargos como Ministros de Educación, los ideales estudiantiles que lideraron no se materializaron en sus gobiernos.

Palabras clave: Educación; universidad; movimiento de estudiantes; generación del centenario, Córdoba.

\section{ABSTRACT}

The aim of this paper focuses on analyzing two student leaders, who lived the centennial period of the American independence, and simultaneously they also experienced the time of the Colombian student movement and the incidence of Cordoba's one in the Latin American region. We refer to Luis López de Mesa (1884-1967), centenary generation: and Germán Arciniegas (1900-1999), generation of new leaders.

The historical period covers from 1910 to 1924 corresponding to the first and second Colombian student Congress. From the political history are analyzed these two student leaders, who occupied the ministry of education under liberal governments. Both were dedicated to university teaching and were characterized by their contributions to journalism and their new approaches towards a reform of the Colombian university. Their conceptions on education and their university proposals are studied here from the perspective of the student movements and especially from the features adopted from Cordoba's Movement in Colombia. The comparative methodology was used for this study and is based mainly on primary sources.

Keywords: Education; university; student movement; generation of the centenary, Cordoba.

\section{RESUMO}

O objeto deste trabalho consiste em analisar dois líderes estudantis que viveram o período do centenário da independência americana, mas, por sua vez, corresponderam à época do movimento estudantil colombiano e à incidência de Córdoba nesta região latino-americana. Nos referimos a Luís López de Mesa (1884-1967), geração do centenário, e Germán Arciniegas (1900-1999), geração dos novos. O período histórico se toma de 1910 a 1924, que corresponde ao primeiro e segundo Congresso estudantil colombiano. A partir da história política, se analisará a estes dois líderes estudantis que logo ocuparam o ministério da educação sob governos liberais. Caracterizaram-se pela docência universitária, contribuições no jornalismos e novas abordagens de reforma desde a universidade colombiana. São duas figuras que foram estudadas desde a 
concepção que tinham sobre a educação, a universidade e suas propostas universitárias desde a perspectiva dos movimentos estudantis e em especial o que chegou do Movimento de Córdoba à Colômbia. Foi usada a metodologia comparada, sustentada principalmente em fontes primárias.

Palavras-chave: Educação; universidade; movimento de estudantes; geração do centenário, Córdoba.

\section{INTRODUCCIÓN}

Para poder entender la generación estudiantil colombiana del centenario y la de los nuevos, los ubicamos en el contexto socio-político de la época, porque el movimiento estudiantil es un hecho social y estas dos generaciones presentan un sello que es el de la identidad latinoamericana. Estos jóvenes estudiantes establecieron relaciones, con sus homólogos de los diferentes países latinoamericanos, porque los contextos de problemas políticos eran similares en cada uno de sus países. Es relevante indicar que, en las concepciones teóricas del estudio, para esta época no utilizaremos el concepto de joven ${ }^{6}$, sino que acogemos los aportes de movimiento estudiantil que nos dan los historiadores Renate Marsiske al señalar que a "los estudiantes y los movimientos tienen relaciones muy estrechas con el estado general de la sociedad y la calidad y la orientación de su vida política"7. Por su parte, Álvaro Acevedo, como analista al movimiento estudiantil del 68, expresa "La juventud es un campo de confrontación de intereses y poderes, no solo por la definición como etapa de la vida, sino por el control que toma de decisiones" ${ }^{\prime 8}$. Lo evidente para los dos autores, y en este trabajo, es el hecho social-político de contexto, en el que se circunscribe el movimiento estudiantil. En este caso, las fuerzas encontradas son las del partido conservador y las de los liberales con las nacientes socialistas que aparecen en el país y que marcarían rupturas en el pensamiento político y en las representaciones sociales ${ }^{9}$.

De esta manera, al introducirnos en los antecedentes de estas dos generaciones, localizamos el origen en las ideas políticas de los liberales radicales que, quizá en su imaginario, deseaban rescatar para dar soluciones desde la educación a una Colombia convulsionada en los inicios del siglo XX. Fue también evidente que las ideas políticas y de cambios culturales estaban en la palestra del movimiento estudiantil latinoamericano.

6 El concepto de joven varía según los contextos socio-político-culturales de cada época histórica. Véase en Alpízar y Bernal (2003, 121) y Duarte, K. (2000). ¿ Juventud o juventudes? Versiones, trampas, pistas y ejes para acercarnos progresivamente a los mundos juveniles. Última década, 13.

7 Renate Johanna Marsiske Schulte, “Clases medias, universidades y movimientos estudiantiles en América Latina 1900 - 1930”, en Movimientos Estudiantiles En La Historia de América Latina, ed. Universidad Nacional Autónoma de México. (México: Universidad Nacional Autónoma de México, 1999) 142 - 158.

8 Álvaro Acevedo Tarazona, 1968 Historia de un acontecimiento: Utopía y revolución en la universidad colombiana. (Bucaramanga, Publicaciones UIS, 2017), 33.

9 Denise Jodelet, "El movimiento de retorno al sujeto y el enfoque de las representaciones sociales", Revista Cultura y Representaciones Sociales. Vol. 3, No. 5 (2008): 32-63. Denise Jodelet, "La representación social: fenómenos, concepto y teoría Psicología Social II. Pensamiento y vida social. Psicología social y problemas sociales", compilado Moscovici, S. (comp.). (Barcelona, Ediciones Paidós). 
La investigación se sustenta en la historia sociopolítica y ubica al antioqueño Luis López de Mesa (1884-1967) como eje central de análisis, en la generación del centenario, y como representante de la generación de los nuevos; al estudiante Germán Arciniegas (1900-1999). Estos dos grupos se unieron en objetivos conjuntos por la reforma educativa universitaria y utilizaron el periodismo como el principal medio de expresión e impacto para sus ideas. La metodología parte de la interrelación del contexto sociopolítico con el movimiento estudiantil y el periodismo bajo el marco de una identidad latinoamericana. Las fuentes se basan en legislación, correspondencia, prensa y documentos de la época. Se concluye que la generación del centenario y la generación de los nuevos se unieron a través del periodismo y plantearon la reforma universitaria del cogobierno bajo la influencia del movimiento estudiantil de Córdoba. Sin embargo, los líderes estudiados en su periodo gubernamental de ministros de educación no lograron los objetivos del movimiento estudiantil.

\section{La convulsión política de inicios del siglo $\mathrm{XX}$, germen del movimiento es- tudiantil colombiano}

En Colombia, el siglo XX se inicia con el hecho político de reafirmar la derrota de los liberales radicales, que correspondían quizá a esa ideología de la burguesía revolucionaria, y que habían perdido el poder con la aprobación de la Constitución de 1886 y el Concordato de $1887^{10}$. Quedaban atrás, las reformas sociopolíticas que sustentaban una visión laica de la educación en Colombia. Por lo tanto, a las dos generaciones: centenario y nuevos, les corresponde su etapa de formación en la época de la hegemonía Conservadora que inicia en 1886 durante el Gobierno del Presidente Rafael Núñez, periodo denominado la Regeneración que finaliza en 1930 con el Gobierno de Pedro Nel Ospina (1926- 1930).

Se debe destacar que se ingresa al siglo XX con la guerra de los Mil Días y la toma de Panamá por parte de los Estados Unidos en 1903. El primer hecho marca una derrota más para los radicales e implica el fortalecimiento del grupo político conservador. El segundo, corresponde a la continuación de una serie de acontecimientos, a partir del tratado de 1846, en los cuales Estados Unidos sienta las bases para apoderarse de la provincia de Panamá y luego de sucesivas agresiones militares dirigidas a desintegrar nuestro territorio y a imponernos condiciones y privilegios, este país logra al final su objetivo: la toma de Panamá y le gana de esta manera la disputa a Inglaterra y Francia sobre este territorio americano.

Es importante indicar que el período anterior (1880 - 1900), a la reforma educativa de la Ley 39 de 1903, diferentes historiadores lo han catalogado como de grandes cambios. Por ejemplo, el historiador Jorge Orlando Melo, lo caracteriza

10 Constitución Politica de la República de Colombia. Poder legislativo. "Preámbulo. En nombre de Dios, fuente suprema de toda autoridad". Presidente del Consejo Nacional Constituyente. Delegado por el Estado del Cauca Juan de Dios Ulloa. Poder Ejecutivo Nacional 5. de agosto de 1886 J.M. Campo Serrano. Publicado D.O. Nos. 6758 - 6759. Año XXII. (Bogotá, sábado 7 de agosto de 1886), 801-807. 
como de "agitación social, de crisis económica y de enfrentamiento político que remata en una larga y sangrienta guerra civil"11. En esta época se suceden cuatro guerras civiles 1876, 1885, 1895 y la de los Mil Días que correspondió al periodo de 1899 a 1903 y en la cual participó el antioqueño Rafael Víctor León Uribe Uribe (1859-1914), quien fue uno de los primeros en proponer la autonomía universitaria en la Cámara de Representantes de Colombia en 1909. Podríamos decir que, dentro de la generación de los radicales, en ese momento encabezada por Rafael Uribe ${ }^{12}$ se luchó por reivindicaciones progresistas en el orden económico, político, cultural y educativo, en el marco de la generación del centenario. Desde luego, en este marco de referencia se podría indicar que la derrota del general Uribe Uribe coincide con la caída de nuestro país bajo el dominio de Estados Unidos. Esta derrota se debió fundamentalmente a la debilidad económica y política de la burguesía liberal y a las presiones y amenazas de los Estados Unidos llevadas a cabo con la complicidad del gobierno conservador, representante de los terratenientes.

Un hecho más, este periodo de la Regeneración iniciado por el cartagenero Rafael Núñez (1825-1894), con su primera administración (1880-1882) trajo de vuelta la religión y las ideas tradicionales que continuaron durante su segunda administración (1884-1886), culminado con la expedición de la Reforma Constitucional del 5 de agosto de 1886 y el Concordato del 31 de diciembre de 1887. De esta manera, se derrotaba la tendencia política de los liberales radicales, dentro de la cual se forma la generación del centenario, pero por muy sorprendente que pudiera parecer lo anterior, esta generación se educaba en familias liberales y esto era determinante.

11 Jorge Orlando Melo, La evolución económica de Colombia 1830-1900 (Bogotá: Manual de Historia de Colombia, tomo II, Instituto Colombiano de Cultura, 1979), 659.

12 El General Rafael Uribe Uribe nació el 12 de abril de 1859 en la hacienda "El Palmar" jurisdicción de Valparaíso (Antioquia). Se gradúa de Abogado en 1880. Funda, en Medellín 1881, el periódico "El Trabajo". En la guerra civil de 1885, derrotado, en Antioquia es hecho prisionero, y en la cárcel escribe: "Diccionario de corrección del lenguaje"; "Tratado de Geología al alcance del pueblo", y una "traducción de Spencer y su defensa judicial". En 1893, se radica en Bogotá, mientras su partido (El Liberal) atraviesa momentos excepcionalmente difíciles. Se levanta en armas contra el Gobierno, es derrotado el dos de enero de 1895 en el Tolima, es llevado prisionero a Cartagena. Consigue la libertad y huye a Centro América. En 1896 regresa y llega a la Cámara como único vocero del Partido Liberal. Su mejor discurso: "sobre la libertad de Cuba". Propone irónicamente que el Congreso de Colombia se declare partidario del colonialismo y que pida a España hacerse cargo del país otra vez. El 17 de octubre de 1899, estalla la revolución (guerra de los mil días), y Uribe vence en Santander, aunque a costa de grandes pérdidas. Las derrotas de Uribe, le obligan a retirarse a Ocaña. Luego pasa a Venezuela, en busca de ayuda y posteriormente a los Estados Unidos. Regresa y combate en los Llanos Orientales y más tarde en la Costa. En 1902, capitula ante el General gobiernista Juan B. Tovar. El Minguerra de entonces, José Joaquín Casas, ordena desde Bogotá, el fusilamiento de Uribe Uribe, pero el General Tovar, se niega indignado. En 1905 ejerce misión diplomática en Chile, Argentina y Brasil, y en 1906 representa brillantemente a Colombia, en la Conferencia Panamericana de Río de Janeiro. Tendré el honor de presentar ante la Cámara, algunas aspiraciones socialistas: "participación de los obreros asalariados en las ganancias de la industria o explotación en que se ocupan; organización oficial en las Cajas de Ahorros puestas al alcance de todos los asalariados para liberar a las masas obreras de la esclavitud de la imprevisión, como la instrucción gratuita y obligatoria ha libertarias de la esclavitud de la ignorancia; creación de bancos de anticipo que hagan préstamo al obrero para ayudarle a establecerse; fundación de bancos hipotecarios que desempeñen el mismo papel respecto a la agricultura; desarrollo de los seguros y de todos los sistemas cooperativos; medidas preventivas y aún coercitivas contra el alza artificial de los víveres y demás artículos de primera necesidad, no permitiendo la compra a los revendedores, sino después de haberse surtido. Creemos que es necesario dictar leyes sobre los accidentes de trabajo y protectoras del niño, de la joven y la mujer en los talleres, y en los trabajos de campo; creemos que se debe obligar a los patronos a preocuparse de la higiene, del bienestar y de la instrucción gratuita de los desamparados. El socialismo que defiendo difiere tanto del absolutismo que mata la dignidad humana, como el individualismo que mata a la sociedad. La postura política de Uribe: "La reforma agraria, las prestaciones sociales, la educación gratuita y obligatoria, los movimientos migratorios dirigidos dentro el propio país, la industria cafetera. Tomado: Revista Semana. La revista nacional de noticias. Rafael Uribe Uribe. Cien años de historia colombiana 1859-1959. El testamento de Uribe Uribe. Las ideas de Uribe Uribe, Segunda época. No. 640-64. Bogotá, del 7 al 13 de abril de 1959, 17, 18 y 19. 
En este sentido, cabe anotar dentro del proceso histórico, que la diferencia respecto al laicismo fue una característica que se dio en los dos partidos políticos de liberales y conservadores. Por este motivo, las diferentes constituciones marcaban la discrepancia al iniciar las Constituciones que se promulgaron. En tal sentido, la constitución de 1863 (febrero 18), también llamada constitución de Ríonegro, había suprimido en su encabezamiento el nombre de Dios. Por el contrario, la Constitución de 1886 se inicia indicando: "en nombre de Dios, fuente suprema de toda autoridad, a fin de afianzar la unidad nacional y asegurar los bienes de justicia, la libertad y la paz".

Un segundo aspecto de la discrepancia corresponde al centralismo y federalismo como forma administrativa del gobierno. Las razones para ello eran poderosas. Los liberales dieron plena soberanía a los Estados en 1863, y el país recibió el nombre de Los Estados Unidos de Colombia. Por su parte, los conservadores cambian en 1886 la forma organizativa y aprueban la forma unitaria que le dio el nombre de República de Colombia a la nación. A los estados territoriales les dieron el nombre de Departamentos.

Un tercer aspecto del desacuerdo radicaba en las libertades. Los liberales defendían las individuales, de imprenta, de expresión oral y escrita, y de cultos. Por lo tanto, para garantizar estas libertades, el Estado ejercía la suprema inspección sobre las mismas. Por otra parte, los conservadores abogaban por las libertades de la educación laica pero supervisada por la religión católica. He ahí la diferencia. De hecho, los liberales declararon en 1863 a las comunidades religiosas incapaces para adquirir bienes raíces, y por el contrario, la constitución conservadora de 1886 estableció a la religión católica como la única de la nación, obligando a los poderes públicos a protegerla y respetarla "como esencial elemento del orden social". Un cuarto aspecto, vinculado al anterior, es la separación Iglesia-Estado que constituye una de las principales diferencias entre estas dos constituciones; 1863 y 1886. Por supuesto, esto conllevó a que la de 1886 estableciera que la educación pública quedara organizada en concordancia con la religión católica, y se le dio plena libertad a la iglesia para intervenir en ella.

Por todo lo anterior, podríamos decir que en la constitución de 1863 predomina el federalismo y las libertades individuales y se separa la iglesia del Estado. En cambio, la de 1886 se caracteriza por el centralismo, se "vigoriza la autoridad" y se definen las libertades individuales; se le dan todas las garantías a la iglesia para que tutele la educación, hecho que se reafirma el 31 de diciembre de 1887 con el Concordato. Es así que Núñez planteaba que en su concepto "la legislación debía unificarse y la administración pública ser nacional, el sistema educativo tendría por principio la religión católica, justicia y libertad son entidades armónicas y en este principio deben fundarse las libertades individuales." ${ }^{13}$

Por otra parte, es una etapa durante la cual surge la industrialización en Colombia. Por ejemplo, la fábrica de ácido sulfúrico que organizaron Saldarriaga

13 Jesús María Henao, y Gerardo Arrubla, Historia de Colombia para la enseñanza secundaria (Librería Colombiana, C. Roldán \& Tamayo, 1952),782. 
y compañía en Medellín (1886). En Samacá se fundó una fábrica de tejidos e hilados (1886) que ya en 1893 ocupaba 100 obreros. En 1881 se estableció una ferretería en Pacho (Cundinamarca) y en 1886 en Amagá (Antioquia). Se establecieron cervecerías en Neiva, Bucaramanga y Cali. En 1891 se fundó la fábrica cervecera de Bavaria en Bogotá. En Caldas, Titiribí y Copacabana se fabricaron aparatos para beneficiar el café. Igualmente, se establecieron fábricas de calzado. Destacamos que en 1899 en Cajicá se estableció una empresa para producir sal, Luis Ospina Vásquez, considera que "casi todas estas empresas tuvieron efímera duración, pero algunas prosperaron"14.

En este contexto, la generación del centenario de 1910, se caracteriza por las ideas modernizantes respecto al Estado, por prestar gran interés a la educación y por sus marcados vínculos internacionales. Se destaca la aparición de dos españoles: Pablo Vila (1881-1980) ${ }^{15}$ y Miguel Fornaguera i Ramòn (1893-1988) ${ }^{16}$, vinculados en amistad con Agustín Nieto Caballero (1889-1975), quienes colaboraron en la dirección y como profesores del Gimnasio Moderno en Bogotá. En esta generación destacamos a Rafael Uribe Uribe (1859-1914), Tomás Rueda Vargas (1879-1943), Luis López de Mesa (1884-1967), entre otros. Por otra parte, en Colombia, la Generación de los nuevos, que se caracterizó por participar en la política desde el partido liberal, algunos socialistas, participaron en los movimientos estudiantiles, fundaron revistas y se preocuparon por la reforma universitaria. Entre algunos de sus exponentes están: Germán Arciniegas (19001999), Jorge Eliécer Gaitán Ayala (1903-1948), Gerardo Molina (1906-1991), Francisco Socarrás (1906-1995), y Gabriel Turbay (1901-1947).

Es importante señalar que, en España, la Generación del 98 está en la palestra, surgida en los inicios del siglo XX, como una tendencia para modernizar el país y establecer cambios educativos y culturales. Se localiza entre otros exponentes a Miguel de Unamuno (1864-1936), con pensamiento marxista y vinculado a la Universidad de Salamanca. Así mismo, la generación del novecentismo o Generación del 14, que se caracterizaron por la transformación cultural, el reformismo, el periodismo. Figuras que se destacan como Ortega y Gasset (1883-1955) ${ }^{17}$, Francisco Giner de los Ríos (1839-1915) ${ }^{18}$, y el pensamiento de la Institución Libre Enseñanza ${ }^{19}$ que llegaron a Latinoamérica a través de españoles

14 Luis Ospina Vásquez, Industria y protección en Colombia, 1810-1930 (Bogotá: la oveja negra, 1955), 300-317.

15 Está en el Gimnasio Moderno de 1915 a 1918 y luego regresa a Colombia en 1939 en calidad de exiliado y trabaja como profesor en la Escuela Normal Superior. En 1945 publicó el libro la Geografía en Colombia

16 Llegó a Bogotá en 1915, regresó a España en 1933 pero luego se regresa como exiliado y muere en Bogotá en 1988.

17 José Ortega y Gasset ( $\underline{1883}$ - 1955$)$ estuvo exiliado en Argentina hasta 1942 cuando se va para Portugal. Fue profesor de la Escuela Superior de Magisterio de Madrid (1909). Al igual de Luzuriaga estudio en Alemania. Pertenece al movimiento denominado novecentismo.

18 Francisco Giner de los Ríos (1839-1915) fue director de la Institución Libre de Enseñanza (ILE). Véase Francisco Giner. Educación y enseñanza Tomo XII. (Madrid, Espasa Calpe,1933), 20. Obras completas de Francisco Giner se publicaron en 1889 en la Biblioteca Andaluza. Los trabajos de este tomo fueron publicados por Giner en el Boletín de la Institución Libre de Enseñanza. En este texto analiza la situación de los maestros españoles de fin del siglo XIX, con la extrema pobreza, de salarios de 125 pesetas anuales ganado según él menos que el "harapiento bracero", 20.

19 La Institución Libre de Enseñanza o ILE, fue fundada por Francisco Giner de los Ríos en 1876 en España. Esta institución se originó por un grupo de docentes, de la Universidad Central de Madrid, como un acto de rechazo al hecho de haberse suprimido en la Universidad Central de Madrid la libertad de Cátedra. La corriente filosófica que sustentó esta institución fue la de Karl Christian 
como Lorenzo Luzuriaga Medina (1889-1959) ${ }^{20}$, quien perteneció al grupo de españoles socialistas que se exiliaron en Latinoamérica ${ }^{21}$, durante el período del dictador Franco, y en Colombia los citados previamente Vila y Formaguera.

Es importante resaltar que para esta época el café se convertía en nuestra principal fuente de exportación. En 1880 se exportaban 5.000 toneladas y estas ascendieron en 1900 a 21.625 y en 1905 a $32.500^{22}$. Se considera que con estos intentos de industrialización y con la construcción de vías de comunicación (ferrocarriles, caminos) y obras públicas, "surgen los primeros elementos de clase obrera moderna, aunque pasaron varios decenios, hasta después de la primera guerra mundial, sin que se lograra un importante desarrollo." ${ }^{23}$

Cabe anotar que el contexto político convulsionado no era exclusivo de Colombia. Esta situación era similar en los demás países de América Latina y de allí surgen los movimientos obreros y estudiantiles que a finales de los años $20 \mathrm{y}$ con la revolución rusa (1917) introducen nuevas formas de pensamiento político que permean los movimientos estudiantiles en este país latinoamericano, caracterizado por la ruralidad y que en 1912 no superaba los 5 millones de habitantes y reportaba unas rentas nacionales de 12 millones de $\operatorname{pesos}^{24}$.

\section{La generación del centenario y de los nuevos. Reformas y congresos de es- tudiantes}

La educación desde el siglo XVIII, con el movimiento cultural de la Ilustración y la administración de Carlos III en España, se convierte en un pilar fundamental para las transformaciones políticas ${ }^{25}$, donde los movimientos estudiantiles saltan a la palestra ${ }^{26}$. Se atraviesa el siglo XIX en medio de guerras donde la orientación laica o religiosa se convierte en motivo de controversia. Es así como inicia el siglo XX con la ley 39 de 1903, llamada también la Reforma Antonio José Uribe, que tiene su antecedente inmediato en la reforma Constitucional del 5 de agosto de $1886^{27}$.

Friedrich KrauseKarl Christian Friedrich Krause (1781-1832), filósofo alemán que desarrolló el panenteísmo y que sustentó teóricamente el krausismo. El Dios del panenteísmo es el creador y la energía vital del universo, así como la fuente de la ley natural, por lo que es trascendente e inmanente.

20 Lorenzo Luzuriaga Medina (1889-1959), pedagogo español que se exilió en Argentina y murió en Buenos Aires.

21 Obras como "Mi credo pedagógico" de Laurent Bonardi, Dewey. "Les intellectuels espagnols exilés dans largentine peroniste", en Haol, No. 5 (2004): 53-64, consultada en línea. En este artículo se destaca la producción académica de los exiliados españoles en Argentina. Véase una amplia biografía en wikipedia.org/ wiki/Lorenzo_Luzuriaga, consultada el 30 de mayo del 2013.

22 Eduardo Peña Consuegra, Origen y desarrollo de la burguesía colombiana. (Barranquilla: Tipografía Dovel, 1971), 82.

23 Eduardo Peña Consuegra, Origen y desarrollo de la burguesía colombiana. (Barranquilla: Tipografía Dovel, 1971), 82.

24 Armando Suescún Monroy "Datos para un balance de la universidad colombiana en el siglo XX", en Movimientos universitarios en América Latina, ed. Olmedo Vargas Hernández (Tunja: RUDECOLOMBIA, 2005), 29 - 46.

25 Diana Soto Arango. "El movimiento de estudiantes y catedráticos en Santa Fe de Bogotá a fines del siglo XVIII", en Movimientos estudiantiles en la historia de América Latina, ed. Renate Marsiske (México: Universidad Nacional de México, Plaza y Valdés Editores, 1999), $40-60$.

26 Diana Elvira Soto Arango. Polémicas universitarias en Santa Fe de Bogotá. Siglo XVIII. (Bogotá: Universidad Pedagógica Nacional, 1993)

27 Asi mismo, en el Decreto 596 sobre instrucción pública y profesional del 9 de octubre de 1886, en el concordato del 31 de diciembre de 1887 y en el Plan Zerda de 1892. Decreto 595 de 1886 (9 de octubre) "Por el cual se organiza la Instrucción Pública Primaria" Art. 25. En todas las escuelas, así normales o primarias, se enseñará la religión católica" presidente J.M. Campo Serrano. Ministro de 
De esta manera, la Ley educativa de 1903 es una continuación de la ideología conservadora en el aspecto educativo que se implementó a partir de 1886 bajo la hegemonía conservadora. Lo destacable es que el grupo del centenario, hijos de las guerras civiles del siglo XIX entre liberales y conservadores, donde en cada caso se borraban los vestigios de las reformas de sus antecesores y se imponía la ideología de su partido. En este sentido, antes había primado (1863-1886) la ideología liberal, pero a partir de 1886, como lo hemos indicado, con el nuevo gobierno, se cambia la concepción educativa fundamentalmente en el campo religioso que se contrapuso a la reforma Educativa de los radicales. ${ }^{28}$

Precisamente, la generación liberal del centenario vivió a través de sus padres y en su corta edad, para algunos, la reforma educativa de 1870 que establecía una educación laica ${ }^{29}$ y que luego fueron testigo de los cambios radicales en la nueva reforma de la constitución de 1886, que expresar en el Art. 41: "la educación pública será organizada y dirigida en concordancia con la religión católica y la instrucción primaria costeada con fondos públicos, será gratuita y no obligatoria, y el Art. 12 del concordato de $1887^{30}$ señala: "en las universidades y colegios, en las escuelas y en los demás centros de enseñanza, la educación e instrucción pública se organizará y dirigirá en conformidad con los dogmas y la moral de la religión Católica." 31

En definitiva, para ese momento el panorama educativo era dirigido por la ideología conservadora e incidía en la formación y desempeño docente." ${ }^{32} \mathrm{De}$ esta manera, el conservador Antonio José Uribe, toma de base para su reforma de 1903, entre otros aspectos; la no obligatoriedad, y el predominio de la iglesia y la religión católica en la educación. Sin embargo, en la misma época iniciamos el nuevo siglo con las figuras señeras de los liberales radicales de la generación del centenario como Rafael Uribe Uribe (1859-1914), Luis López de Mesa (18841967), Agustín Nieto Caballero (1889-1975), Tomás Rueda Vargas (1879-1943), entre otros, unidos en un interés común por la literatura, pero, ante todo, por sus planteamientos sobre otro tipo de educación, donde la universitaria tenía un objetivo central. A esta generación les correspondió la celebración del centenario

Instrucción pública José Domingo Ospina Camacho.

Decreto 544 de 1888 (14 junio) "Sobre enseñanza y prácticas religiosas en los establecimientos de instrucción pública: Art. 1. En todas las Escuelas Oficiales, así primarias como normales, se enseñará la Religión Católica”. Art. 2 "En todos los Institutos universitarios y colegios incorporados en la Universidad Nacional el curso de Religión Católica figurará ante los de filosofía y letras determinadas por el artículo 14 del Decreto N. 596 de 1886. D.O.N.7422 Año XXIV. Bogotá, lunes 18 junio de 1888. p. 636. Presidente Rafael Núñez, Ministro de Instrucción pública J. Casas Rojas.

28 del 10 de noviembre de 1870 .

29 Reforma Educativa de 1870, en el capítulo I, Art. 36 plantea que el gobierno no intervendrá en la educación religiosa, el Art. 38, se elimina la cátedra de Religión del Plan de Estudios, el Art. 102, se refiere a la obligatoriedad de la educación primaria.

30 El concordato celebrado en 1887, entre S.S. LEÓN XIII Representado por el Cardenal Rampolla y el Presidente de la República Rafael Núñez, Delegado por Colombia el Dr. Joaquin Vélez. "El concordato es esencialmente un convenio destinado a delimitar las órbitas de la acción de la Iglesia y del Estado en aquellos asuntos que por su naturaleza participan en las potestades". Ley 35 del 31 de diciembre de 1887.

31 Ivón Lebot. Elementos para la historia de la educación en Colombia en el siglo XX, en Boletín Mensual de Estadística $N^{\circ} .249$ DANE, (Bogotá: 1975), 147.

32 Decreto 596 del 9 de octubre de 1886 en el título 5 se incorpora a la Universidad la enseñanza de la cátedra de la religión católica. Es más, en el Plan Zerda, en su decreto reglamentario 349 de 1892, en su Art. 5 "establece que los maestros serán nombrados por el gobierno Departamental y deben poseer "buena conducta y profesar la religión católica óp, cit. p. 146. Nota: la Ley 39 de 1903 fue consultada en el libro Blanco. Universidad Pedagógica Nacional. 
y en el campo universitario, y la organización y participación en el primer Congreso Nacional estudiantil en 1910. Estos personajes que hemos ubicado en la generación del centenario plantearon un nuevo ideal de universidad que desde las condiciones políticas de un país con la ideología conservadora se atrevieron desde la universidad pública a trazar nuevos derroteros coincidentes con el movimiento estudiantil de Córdoba.

Quizá sea Gerardo Molina quien mejor describa a esta generación del centenario, cuando señala que "Los hombres del Centenario se dirigían por medio de la palabra escrita a las grandes aldeas que eran las ciudades colombianas en los primeros decenios de este siglo. La gente analfabeta de los campos, con la cual era imposible establecer una comunicación, les interesaba muy poco, pues la suponía dominada por el cura, el alcalde y el cacique, instrumentos del régimen conservador o de los caudillos en trance de alzamiento armado. En tales condiciones, los esfuerzos se concentraron en ensanchar la franja de las aglomeraciones urbanas, y fomentar mediante las obras públicas y las industrias el traslado de los campesinos a las ciudades para poder extender el imperio de la civilización europea" 33 .

Pero a su vez, Gerardo Molina establece un balance de esta generación que según él no logró los ideales propuestos "para nosotros la principal realización del grupo Centenario fue haber preparado el país para el establecimiento de la República Burguesa. Lo que se echa de menos en sus componentes es una perspectiva amplia del desarrollo nacional. Si hubieran trabajado por una serie de cambios destinados a establecer un capitalismo democrático y a eliminar los restos feudales, si su antiimperialismo hubiera sido una postura entrañable y no meramente episódica, si no se hubieran satisfecho con la democracia y las libertades formales". ${ }^{34}$

Más adelante, esta generación se uniría con la de los nuevos, que nacen en los inicios del Siglo XX, y se caracterizan por pertenecer al partido liberal y algunos al naciente socialista, por su interés en el periodismo, y su preocupación por la educación; especialmente enfocada en la reforma universitaria. Varios de ellos se desempeñaron como profesores y rectores universitarios. Podríamos añadir

33 Gerardo Molina (1974) Las ideas Liberales en Colombia 1915-1934. Ediciones Tercer Mundo. Primera edición agosto 1974. Capítulo VII La Generación del Centenario y las ideas liberales. Obra publicada bajo el patrocinio de la universidad Nacional de Colombia. Derechos Reservados Ediciones Tercer Mundo. Homenaje a Jorge Zalamea y Luis Eduardo Nieto Arteta. Gratitud al doctor Manuel José Cárdenas. Decano de la Facultad Nacional de Derecho y a los demás Miembros del Consejo Directivo. 67- 76.

34 Gerardo Molina (1974) Ex Rector Universidad Nacional. Ex Representante. Ex Senador, su nombramiento reciente en la rectoría de la universidad Libre, había estimulado allí una notoria actividad marxista. Se le acusó de ser miembro del Partido Comunista Colombiano-PCC y de infiltrar dentro del profesorado y en la sala de Gobierno de la Universidad. Molina, afirma que la encontró semejante a la que tuvo que afrontar hace 9 años cuando dirigía la U. Nacional (1947) y le endilgaron el mismo peligroso adjetivo de marxista. La cátedra abierta. El problema, inexistente, a que se han referido algunos periódicos, reside en el poco conocimiento de los hechos sociales. En Colombia, que no es un país socialista, ni mucho menos comunista, no puede haber una universidad socialista o comunista, pues la universidad es parte de la vida social. La Universidad Libre es una cátedra abierta que no selecciona alumnos o profesores con criterio de secta. En cuanto a la infiltración comunista, puedo decir que ella no existe como tal. Lo que ocurre es que por el mismo carácter de libre de la Universidad, en algunas cátedras, existen profesores de ideología marxista, así como hay otros conservadores, otros socialistas, otros, la gran mayoría liberales. Estos profesores de tendencias socialistas tienen libertad para exponer sus tesis y los estudiantes conservan, también, toda la libertad para seguirlas o no. El marxismo se enseña también, respetando la conciencia de los estudiantes, porque es una doctrina que no debe ignorar ningún universitario de ciencias sociales en la época actual". Tomado: Revista Semana. Una revista de hechos y gentes de Colombia y del mundo. Volumen XXI No. 503 Bogotá, julio 9 de 1956. Página 10. El Rector Gerardo Molina. Discípulos retozones. 
que también les correspondió el período de participación y dirección del partido liberal cuando regresó al poder. Este grupo participó en el segundo congreso nacional de estudiantes (1924), promovieron huelgas, fundaron la Federación de Estudiantes (1922), la casa del estudiante en Bogotá, revistas universitarias como "Voz de la juventud" y "La Universidad" (1921) ${ }^{35}$, y las revistas literarias de "Los Nuevos"36, y la "Pánida" en Medellín. Entre los exponentes podemos indicar, entre otros a Germán Arciniegas (1900-1999), Adolfo Gil Hernández (1903-1978), Gerardo Molina (1906-1991), Francisco Socarrás ${ }^{37}$ (1906-1995) ${ }^{38}$, Gerardo Molina (1906-1995), Jorge Eliécer Gaitán Ayala (1903-1948), Gabriel Turbay (1901-1947)39.

Hay que tener en cuenta que esta generación de los nuevos, o de la posguerra, tuvo especial vigencia entre 1940 y 1960 en los cargos políticos, pero le correspondió la época del segundo Congreso de estudiantes en 1924. En aquella época, los escritores de esta Generación se reunieron alrededor de dos revistas literarias: la revista de "Los Nuevos", dirigida en Bogotá por los escritores Alberto Lleras Camargo y Jorge Zalamea Borda; y la revista "Pánida" en Medellín.

Hasta ahora el hecho más destacable es que a estas dos generaciones les une el haber propuesto y defendido la autonomía universitaria para la universidad colombiana. Como hemos indicado, es una época en la cual desde México hasta Argentina, los estudiantes revindican el derecho a participar en el gobierno

35 El 24 de febrero de 1921 editó por primera vez esta revista bajo la dirección de Germán Arciniegas. Se suspendió el 20 de abril de 1922 en el número 34, sin embargo, Arciniegas la reanudo el 27 de junio de 1927 continuando con el número 35. Se dejó de publicar el 21 de septiembre de 1929 en el número 152.

36 Dirigida en Bogotá por los escritores Alberto Lleras Camargo y Jorge Zalamea Borda.

37 José Francisco Socarrás (1906 - 1995) Médico y educador. Maestro de generación normalistas y el ideólogo de la Escuela Normal Superior de Colombia; Institución que se creó para formar a los "Maestros de Maestros". Llamada en su tiempo "El Vaticano de la cultura popular nacional”. El maestro Socarrás realizó estudios secundarios en el Colegio BIFFI de Barranquilla. Se doctoró en Medicina en la Universidad en 1930, con la tesis "principios fundamentales del psicoanálisis". Como rector de la Escuela Normal Superior de Colombia entre 1937 - 1945, imprimió una filosofía propia del hombre colombiano e insistió en la necesidad de aplicar métodos de investigación aplicables."Socarrás, es considerado como uno de los iniciadores en Colombia del psicoanálisis, ciencia mediante la cual se lleva al enfermo a relatar sus experiencias, para que, asociando libremente un recuerdo con otro, pueda dominar los complejos que entraban su personalidad y que constituyen la razón de su estado. Inicialmente, la controversia se trabó acerca del psicoanálisis, tema largamente debatido en los últimos años, pero para especialistas y profanos, el punto central por dilucidar era si Colombia cuenta o no con los medios suficientes para atender las enfermedades mentales. Los expertos sostienen que así el enfermo se hace consciente y proclaman al psicoanálisis como una revolución científica. Sin embargo, otra corriente médica considera que por sí solo no puede curar todos los tipos de la extensa y la compleja gama de enfermedades mentales y que es un sistema complementario. Los métodos de tratamiento son de dos tipos: orgánicos y sicoterápicos. Con los orgánicos (entre ellos electrochoques o la coma insulínica. Con los métodos psicoterápicos, entre ellos el psicoanálisis, por medio de la sugestión o la razón, se lleva al enfermo a que comprenda sus problemas para hacerlo consciente. La relación directa médico-paciente, prescindiendo de tratamientos orgánicos, debe resolverse a este sus conflictos mentales para curarlo. Socarrás, afirma: que la asistencia psiquiátrica es la más abandonada que tiene el país y que, además, se está intentando hacer psiquiatría sin psiquiatras. En Colombia los recursos son ínfimos a tiempo que las personas que requieren sus servicios van en constante aumento. La enfermedad crece y los medios asistenciales permanecen estacionarios. No existe asistencia colectiva sino individual y que esta solo pueden aplicarla cuando los pacientes acuden por lo avanzado de su enfermedad. Socarrás, estudio cuatro años de Especialización clínica en Paris. Defensor del psicoanálisis, en Francia recibió las orientaciones de Paul Cenac, discípulo de Henry Ey y de Paul Giraud”. Tomado: Revista Semana. Una revista de hechos y gentes de Colombia y del mundo. José Francisco Socarrás. La polémica psiquiátrica. Ciencia. Sonido esquizofrénico, Segunda época. No. 649. Bogotá del 2 al 8 de junio 1959, 46, 47 y 48.

38 Fundador del partido socialista. Profesor de Antropología y Facultad de Derecho de la Universidad Nacional.

39 Otros, que se identificaron en lo político y/o literario como León de Greiff; Jorge Zalamea Borda, Rafael Maya, Eduardo Caballero Calderón, Aurelio Arturo, Alberto Lleras Camargo, Carlos Lleras Restrepo, Darío Echandía, Juan Lozano y Lozano, Antonio Álvarez Restrepo, Augusto Ramírez Moreno, Guillermo León Valencia, Gustavo Rojas Pinilla, Gilberto Alzate Avendaño, Silvio Villegas, Fernando Londoño y Londoño, Rafael Torres Quintero, Rafael Bernal Jiménez, Luis Ángel Arango, Germán Pardo García, Eduardo Zalamea Borda, Luis Gabriel Cano, Roberto García Peña, Luis Alberto Acuña, Edgar Negret. 
universitario. Para el caso colombiano, localizamos que desde 1909 se plantea en la Cámara de representantes una primera propuesta de autonomía universitaria.

En definitiva, algunos líderes de esta generación del centenario se vincularon al movimiento estudiantil de 1909, que junto con la protesta popular llevaron a la renuncia de la presidencia del general boyacense Rafael Reyes, el 13 de marzo de ese año ${ }^{40}$. Recordemos que, en ese mismo año el 13 de marzo, se firmó el Tratado Cortés-Root, que formalizó la entrega de Panamá. Pero a su vez, el movimiento estudiantil cobraba fuerza y los representantes liberales ya estaban planteando la autonomía universitaria en el Congreso de la República, dentro de la propuesta de reforma universitaria. Por otra parte, al año siguiente, en julio de 1910, participaron en el Congreso Internacional de estudiantes de la Gran Colombia ${ }^{41}$.

Entre las veleidades autonómicas antecedentes al Movimiento de Córdoba en Colombia, merece destacarse la Reforma propuesta en 1910 por el estudiante Luis López de Mesa (1884-1967), gran agitador universitario, quien con gran audacia propuso ante el Primer Congreso Internacional de Estudiantes de la Gran Colombia, reunido en Bogotá con motivo delCentenario dela Independencia, en la siguiente moción; a probada por unanimidad: “El Primer Congreso Internacional de Estudiantes de la Gran Colombia formula un voto porque las universidades oficiales vayan haciéndose cada día más autónomas, por la participación de los estudiantes en el nombramiento del rector y su justa representación en el Consejo Directivo, por la provisión de las cátedras por medio de concurso y la inamovilidad de los profesores mientras observen buena conducta y no sean vencidos en ellos y excita a los gobiernos de los tres países a proporcionar a las universidades su independencia económica en cuanto fuere posible". La anterior moción fue adicionada con esta recomendación: "El Congreso considerando que la base de la autonomía universitaria es la independencia económica de los establecimientos de instrucción superior recomienda a los cuerpos legislativos, de los tres países, la creación de fondos especiales que serán administrados por las Universidades, sin otra intervención del Estado que la del tribunal destinado a examinar las cuentas". ${ }^{42}$

Años más tarde, este empeño autonomista fue ratificado por la Federación de Estudiantes Universitarios, mediante Declaración expedida en Ibagué en 1918, cuyo Comité Ejecutivo estuvo integrado por Carlos Lleras Restrepo, Diego Luis Córdoba y José Francisco Socarrás.

El entorno histórico en que se realizaría el II Congreso nacional de estudiantes universitarios en 1924, se inscribe aún bajo la hegemonía conservadora. Sin embargo, los estudiantes se reunieron en Bogotá en mayo de $1924^{43}$, para

40 (Medina, 1984: 1932). El 13 de marzo de 1909. Se denominó "El trece marciano" protesta estudiantil dirigida por el estudiante Enrique Olaya Herrera.

41 Álvaro Acevedo. Memorias de una época. El movimiento estudiantil en Colombia en los años sesenta y setenta del siglo XX. (Bucaramanga, Universidad Industrial de Santander, 2016), 59.

42 Antonio José RivadeneiraVargas, El Poder del Saber y los Arquetipos de la Universidad Colombiana, (Bogotá: Academia Colombiana de Historia, 2002), 179.

43 Participaron como delegados de los estudiantes universitarios, adscritos a la Universidad Nacional de Colombia, así: por la Facultad 
llevar a cabo el segundo Congreso Nacional de estudiantes de la República de Colombia $^{44}$. Fue en efecto, visible la participación de la generación de los nuevos, como Germán Arciniegas y Gabriel Turbay, entre otros ${ }^{45}$.

En esta época ya era evidente la influencia del Movimiento estudiantil de Córdoba (1918) y se expresa en el ideal dela unión de los Estados Latinoamericanos en un conglomerado de Naciones, con una política internacional uniforme y un espíritu de solidaridad defensiva ante los peligros comunes que amenazan o puedan amenazar su integridad territorial o los soberanos derechos de su autonomía. Destacamos, en la declaración el manifiesto que indica: “Que son los estudiantes quienes deben llevar a cabo la reforma universitaria, que ellos tienen el derecho de proclamar los nuevos rumbos que deban orientar las actividades de cada Facultad, y la obligación de ponerlos en práctica".

Así mismo, desde los principios del modelo de la universidad de Bolonia ${ }^{46}$, los estudiantes toman las decisiones en la universidad. En este caso se indica que "los universitarios tienen, en consecuencia, el derecho de llevar a las cátedras, como profesores adjuntos o agregados, a quienes juzguen con capacidades de contribuir e cualquier forma a los fines culturales y sociales que persiguen los estudios universitarios, como tienen derecho a disponer de los edificios de la Universidad en el desarrollo de su formación cultural". Igualmente, que ellos pueden abrir las cátedras nuevas que consideren convenientes y suprimir las que no sirvan" ${ }^{47}$. Además, reivindicaban el hecho de asistir libremente a las clases, aboliendo el llamado a la lista.

\section{La autonomía universitaria en Colombia. Un proyecto frustrado en las dos generaciones}

Como se ha señalado en otros trabajos ${ }^{48}$, en el período conservador de Regeneración, no se permiteningún tipo de autonomía universitaria y secentraliza el gobierno de la misma desde la presidencia de la república (1880-1911). El tema

de Derecho: Francisco Samper; José María de la Vega y Manuel Antonio Carvajal; por la Facultad de Medicina: Jorge H. Tascón, Jorge Bejarano y Julio Zuluaga; y por la Facultad de Ingeniería: Enrique Arboleda José María Obando R. y Jorge Montoya. Por la Universidad Republicana: Abel Marín; por el Colegio Mayor de Nuestra Señora del Rosario: Roberto Mantilla Benjamín Iriarte de Odontología y Carlos Pérez de la Escuela de Comercio" Renán Silva Olarte. La educación en Colombia 1880- 1930. Tomo IV Educación y Ciencia. Luchas de la mujer, vida diaria. Nueva Historia de Colombia-NHC. Director Científico y Académico Álvaro Mejía. Asesores Jorge Orlando Melo y Jesús Antonio Bejarano. Planeta Colombiana Editorial. 1989, 84.

44 Dardo Cúneo. La Reforma Universitaria 1918-1930. Compilación, prólogo, notas y cronología. Biblioteca Ayacucho. (Caracas Venezuela, 1988). No. 39. Colombia 1924. Mensaje de la juventud a los Miembros de la Misión Pedagógica. Segundo Congreso Nacional de Estudiantes, 57-66.

45 Néstor Villegas, Eduardo Esguerra Serrano. Mario Correa, Jorge Enrique Bueno, E. Amaya Rubio, P.N. Gómez, Arcesio Mejía M., C.A. Torres Pinzón. Gustavo Esguerra Serrano, Luis E. Mora, Arturo Mejía M. Ricardo Jordán, Moisés Prieto, Pedro C. Ortiz, Jorge Zalamea, Julio Concha, C. Cuellar Wallis, R. Henao Toro. Julián Hernández.

46 Diana Elvira, Soto Arango. La Universidad en el periodo Colonial, (Tunja: UPTC, 2011).

47 Dardo Cúneo. La Reforma Universitaria 1918-1930. Compilación, prólogo, notas y cronología. Biblioteca Ayacucho. (Caracas Venezuela, 1988). No. 39. Colombia 1924. Mensaje de la juventud a los Miembros de la Misión Pedagógica. Segundo Congreso Nacional de Estudiantes, 57-66.

48 Diana Elvira, Soto Arango. "La Universidad Colombiana. Políticas públicas y reformas educativas 1774-2012”, en Historia de la Universidad Latinoamericana, Editora María Cristina Vera, Colección Historia y Prospectiva de la Universidad Latinoamericana, Tomo V, (Córdoba, Universidad de Córdoba, Argentina, 2013). 313-368. 
central es que la universidad se vincula a la Reforma Constitucional de $1886^{49}$, y en este sentido, el Concordato de 1887 da los elementos legales para la "nueva concepción de universidad que entró en vigencia al establecer la universidad confesional y al servicio del partido del gobierno" ${ }^{50}$. El planteamiento de una universidad con una "instrucción Universitaria profunda, severa, y práctica" es introducido por la reforma de 1903 al vislumbrar el siglo XX junto con el inicio de una autonomía universitaria para el año siguiente ${ }^{51}$. Pero será el General Rafael Uribe Uribe en 1909, ante el Congreso de la República, quien señale que la universidad debería ser: "científica, moderna, experimental, actual y evolutiva ${ }^{52}$. El General plantea nuevamente la reforma de la universidad Nacional en su propuesta del 9 de agosto de 1911 donde presenta la autonomía ${ }^{53}$ para esta institución ${ }^{54}$.

Los vientos reformadores de la universidad recorrían América Latina desde el siglo XIX. Los estudiantes abogaban por nuevos estudios y defendían sus libertades. Caso de especial mención es el movimiento de 1875 de los estudiantes mexicanos que promulgaban la enseñanza libre en una universidad libre ${ }^{55} \mathrm{y}$ la del movimiento estudiantil uruguayo con su congreso en 1908.

Hemos indicado que el grupo de la generación del centenario y de los nuevos tenían relación con los jóvenes intelectuales latinoamericanos que soñaban para el siglo XX con una universidad libre donde ellos fueran los regentes del destino de esta nueva institución.

De esta manera, la aportación del periodo denominado "reformismo de la modernidad en la universidad colombiana. 1911-1992"56, es el referente de los hechos conocidos del movimiento estudiantil latinoamericano que va a fortalecer los ideales de autonomía universitaria de los grupos del centenario y nuevos en la República de Colombia. En esta ocasión solo analizaremos hasta el segundo congreso estudiantil de 1924.

Cabe, sin embargo, mencionar que en los inicios del siglo XX la población universitaria en Colombia no pasaba de los mil estudiantes, de los cuales 400

49 El artículo 42 de la Constitución del 5 de agosto de 1886 señala: "La educación pública será organizada y dirigida en concordancia con la religión católica”. El Concordato ley 35 el 31 de diciembre de 1887.

50 Diana, Soto Arango. "Periodos de reforma universitaria en Colombia de la colonia al siglo XXI", Revista Historia de la Educación Latinoamericana, Vol. 16 No. 22, (2014): 277-337.

51 Decreto 491. Objeto. Concibió la Universidad como Científica, Moderna, Experimental y Evolutiva. Señaló levemente la Autonomía Universitaria con el funcionamiento de las facultades (art. 156). Presidente conservador, José Manuel Marroquín. Ministro de Instrucción Pública, Antonio José Uribe.

52 Ley 39 de 1903. Objeto. Establece la necesidad de una instrucción Universitaria fuese profunda, severa y práctica. Presidente conservador, José Manuel Marroquín (del 31 de julio de 1900 al 7 de agosto de 1904). El Decreto número 719 del 8 de julio de 1903 nombra a Antonio José Uribe Ministerio de Instrucción pública.

53 Diana, Soto Arango; María Isabel, Lafuente. Autonomía y modelos universitarios en América Latina. Tomo II (Bogotá, León. Universidad de León, España, Asociación Colombiana de Universidades. ASCUN. Universidad Pedagógica y Tecnológica de Colombia, RUDECOLOMBIA, 2007).

54 Diana Elvira Soto Arango. “Aproximación histórica a la Universidad Colombiana”, en Revista Historia de la Educación Latinoamericana. No. 7 (2005): 99 - 136.

55 María Lourdes, Alvarado. "El movimiento estudiantil de 1875. Entre las demandas académicas y los intereses políticos", en Movimientos estudiantiles en América y Europa. Tomo II, (Córdoba, Argentina), 54 - 55.

56 Diana Elvira, Soto Arango. "Períodos de reforma universitaria en Colombia de la colonia al siglo XXI". Revista Historia de la Educación Latinoamericana Vol. 16, No. 22 (2014): 277-337. 
pertenecían a la Universidad Nacional. Para esta época existían 7 universidades y de estas, 5 eran estatales: La Universidad Nacional en Bogotá, la de Antioquia en Medellín, la del Cauca en Popayán, la de Cartagena, la de Nariño en Pasto ${ }^{57}$. Los movimientos estudiantiles se concentraban principalmente en la capital del país y en la ciudad de Medellín.

Hemos indicado que en 1909 se presentó ante la Cámara de Representantes la propuesta de reforma universitaria donde el punto central era la autonomía universitaria. Es así que el 11 de agosto de 1909 los representantes por las circunscripciones electorales de Bogotá, Jericó y Manizales: Tomás O. Eastman, Juan Pablo Gómez Ochoa, Jorge Martínez y Tomás Samper presentaron un importante proyecto de ley, por el cual se declaraba autónoma la Universidad Nacional y se dictaban otras disposiciones sobre régimen universitario, el cual fue aprobado en primer debate y pasó en comisión para informe al representante Rafael Uribe Uribe. ${ }^{58}$

La aportación de esta propuesta se expresa en el artículo $2^{\circ}$, donde se solicita que la Universidad Nacional "será autónoma en todo lo relacionado con su régimen interior, como nombramiento de Rector y profesores, modificaciones del plan de estudios y elaboración de Reglamento". Y en el artículo $4^{\mathrm{o}}$ se consagraba el avanzado principio de que los alumnos elegirían por votación a los representantes por el tiempo que durara la carrera respectiva, estos representantes constituirían la Diputación de los alumnos, oficiarían como representantes de la comunidad y tendrían un año de duración".

En efecto, consideramos que la propuesta de reforma universitaria es avanzada para su época, especialmente al indicar que el Congreso de Profesores y la Diputación de alumnos elegirá por votación cada dos años al rector y a los miembros del consejo directivo; que se garantizará la inamovilidad de los profesores por el tiempo de su buena conducta y que las vacantes se llenarían por votación del consejo de profesores y la diputación de los alumnos. Sin embargo, como es de suponer en medio del régimen conservador, el hecho de modernizar los estudios universitarios ${ }^{59}$ y plantearse la autonomía en un cogobierno era una reforma que no dejarían pasar los conservadores.

Destacamos la posición del representante liberal Rafael Uribe Uribe, quien defendió que "La Universidad debe ser ante todo nacional en cuanto ha de reflejar la vida del país, tener en cuenta su historia íntima y adoptar sistemas de enseñanza concordantes con el espíritu de la raza"60.

Al respecto, Rivadeneira indica: "Por lo que se colige de los documentos examinados, el representante Uribe Uribe, en vez de rendir la ponencia reglamentaria, presentó un proyecto sustitutivo inspirado en el estatuto de la Universidad de La Plata, Argentina, que ni fue aprobado por la Cámara en sus

57 Suescún Monroy, Armando. óp., cit. 29

58 Anales de la Cámara de Representantes de Colombia, Archivo del Congreso Nacional, 1912, p. 48.

59 Otto, Morales Benítez. Nuevos Aportes de Uribe Uribe al Pensamiento Social, Vol. 10, (Antioquia: Talleres Gráficos de la Imprenta Departamental, 1995), 289.

60 Ibíd., p. 291. 
sesiones ordinarias, ni fue recomendado por el gobierno para las extraordinarias, por lo cual quedó expósito, frustrándose así la posibilidad de que se convirtiera en Ley de la República, pues en tal evento Colombia habría sido la primera nación de América en incorporar a su legislación los principios de la autonomía universitaria que institucionalizó Justo Sierra en México y que inspiraron la reforma de Córdoba ${ }^{61}$.

$\mathrm{Al}$ año siguiente, López de Mesa insiste en el Congreso de estudiantes sobre la necesidad de la autonomía para la Universidad Nacional. Es evidente que los dos grupos de intelectuales ya desde su época estudiantil tenían relaciones internacionales con América Latina y con Europa, ejemplo de ello fueron las misiones pedagógicas alemanas y los académicos que posteriormente se vinculan a las instituciones educativas nacionales.

Este período entre los dos congresos estudiantiles en Colombia (19101924), recibe la influencia del movimiento estudiantil latinoamericano, que se concentra en primera instancia en buscar formas organizativas. En este sentido, se crea en Colombia la Federación de Estudiantes en 1921, bajo el liderazgo de Germán Arciniegas, y cuenta con el apoyo de estudiantes extranjeros como el poeta mexicano Carlos Pellicer, con sueños y utopías ${ }^{62}$ para plasmar en las propuestas estudiantiles. Puede decirse que tenían conocimiento sobre otras federaciones de estudiantes que ya se habían organizado en Brasil (1901), Chile (1906), entre otras. Así mismo, en los albores del siglo XX se organizan congresos internacionales de estudiantes como el de Montevideo con 133 participantes (26 de enero a 8 de febrero de 1908). La relevancia de este congreso consiste en el análisis de planteamientos sobre "Universidad oficial y universidad Libre" 63 y "autonomía universitaria" con la representación de los estudiantes en el gobierno de la universidad ${ }^{64}$.

Destacamos en el III Congreso de la Liga de Estudiantes americanos, que se reunió en el Perú en 1912, donde participó la estudiante Leotilde Luisi, quien presentó un reglamento para la organización de estudiantes ${ }^{65}$. En Colombia pasarían algunos años para que la voz de la mujer estudiante se escuchara en los claustros universitarios.

Pero la Federación de Estudiantes colombianos (1921) estuvo antecedida de publicaciones y huelgas que llevarían a la organización del II Congreso de estudiantes en 1924, en el cual se recopilan los ideales de la autonomía universitaria, unida a la misión pedagógica de los alemanes.

Este congreso se llevó a cabo en Bogotá en mayo de $1924^{66}$ con delegados de los estudiantes universitarios, adscritos a la Universidad Nacional de Colombia,

\footnotetext{
61 Antonio José Rivadeneira Vargas, óp. cit., 176 - 177.

62 Paul Ricoeur. Ideología y utopía. (Editorial Gedisa. Barcelona, 1994).

63 María Cristina Vera. "Un precedente de la reforma del 18: el I Congreso Internacional de estudiantes americanos. Montevideo 1908”, en Movimientos estudiantiles en América y Europa. Tomo II, (Córdoba, Argentina, 2006): 89,90.

64 María Cristina Vera, óp. cit, 93.

65 María Cristina Vera óp. cit, 95

66 Dardo Cúneo. óp. cit, 63, 65.
} 
así: por la Facultad de Derecho: Francisco Samper; José María de la Vega, y Manuel Antonio Carvajal; por la Facultad de Medicina: Jorge H. Tascón, Jorge Bejarano, y Julio Zuluaga; y por la Facultad de Ingeniería: Enrique Arboleda José María Obando R., y Jorge Montoya. Por la Universidad Republicana: Abel Marín; por el Colegio Mayor de Nuestra Señora del Rosario: Roberto Mantilla Benjamín Iriarte de Odontología y Carlos Pérez de la Escuela de Comercio" ${ }^{67}$.

La declaración es expresada a partir de las interpretaciones generales de todos los estudiantes del país, y por lo tanto, afirma en forma solemne "que en el espíritu de la juventud colombiana subsiste vigorosamente el ideal de la unión de los Estados Latinoamericanos en un conglomerado de naciones, con una política internacional uniforme y un espíritu de solidaridad defensiva ante los peligros comunes que amenazan o puedan amenazar su integridad territorial o los soberanos derechos de su autonomía".

Declara, además:

- Que son los estudiantes quienes deben llevar a cabo la reforma universitaria, que ellos tienen el derecho de proclamar los nuevos rumbos de cada Facultad, y la obligación de ponerlos en práctica.

- Que los universitarios tienen, en consecuencia, el derecho de llevar a las cátedras, como profesores adjuntos o agregados, a quienes juzguen con capacidades de contribuir en cualquier forma a los fines culturales y sociales que persiguen los estudios universitarios, como tienen derecho a disponer de los edificios de la Universidad en el desarrollo de su formación cultural.

- Que pueden y están en la obligación de abrir las cátedras nuevas que juzguen convenientes para ampliar los estudios.

- Que la asistencia a las cátedras es libre y el estudiante puede asistir a la que mejor llene sus aspiraciones, bien sea la de los profesores agregados, o la de los titulares, sometiéndose, eso sí, a los programas aprobados por la dirección de la universidad, como trabajo mínimo que está obligado a realizar,

- Que la abolición de la lista es indispensable para consagrar este derecho.

- Que en las Facultades deben formarse consejos de estudiantes para que realicen estas aspiraciones con independencia absoluta de toda tutela oficial $^{68}$.

Estos planteamientos no son nuevos. El II Congreso de estudiantes sintetiza los lineamientos que se venían trazando sobre la autonomía universitaria en Colombia durante el siglo XX, desde 1909. De esta manera se diseñó toda una

67 Renán Silva Olarte. La educación en Colombia 1880-1930. Tomo IV Educación y Ciencia. Luchas de la mujer vida diaria. Nueva Historia de Colombia-NHC. Director Científico y Académico Álvaro Mejía. Asesores Jorge Orlando Melo y Jesús Antonio Bejarano. (Planeta Colombiana Editorial, 1989), 84.

68 De los compañeros delegados en el segundo Congreso Nacional de estudiantes, muy leales compañeros: Germán Arciniegas, Gabriel Turbay, Néstor Villegas, Eduardo Esguerra Serrano. Mario Correa, Jorge Enrique Bueno, E. Amaya Rubio, P.N. Gómez, Arcesio Mejía M., C.A. Torres Pinzón. Gustavo Esguerra Serrano, Luis E. Mora, Arturo Mejía M. Ricardo Jordán, Moisés Prieto, Pedro C. Ortiz, Jorge Zalamea, Julio Concha, C. Cuéllar Wallis, R. Henao Toro. Julián Hernández. Advirtiendo que considera indispensable no solo abrir nuevas cátedras, sino suprimir algunas porque no sirven para nada. Véase en Dardo Cúneo. (1988), 65. 
metodología para que el sector estudiantil hiciera efectivas sus aspiraciones de cambio y de reforma.

Podemos indicar las semejanzas del anterior documento con el referenciado movimiento de Córdoba (1918). En primera instancia, el estudiante es la figura central del movimiento y de la universidad. El documento de los estudiantes colombianos (1924) nos indica que son ellos los que realizan la reforma universitaria y por su parte, los estudiantes de Córdoba reafirman que "la soberanía, el derecho a darse el gobierno propio radica principalmente en los estudiantes" ${ }^{69}$.

Segundo, los estudiantes colombianos (1924), manifiestan que ellos son los que abren las cátedras y las pueden llevar como profesores adjuntos. Por su parte, los estudiantes de Córdoba critican "la casta de profesores" 70 y que ellos son los que pueden designar sus propios profesores. Tercero, los colombianos expresan que en las Facultades deben formarse consejos de estudiantes con el objeto de lograr los objetivos planteados. Los cordobeses exigen que se les reconozca el derecho a participar en los cuerpos universitarios"71.

Como se ha señalado, el tema central es el referente a la libertad universitaria que se cristaliza en las exigencias de participación en los órganos de gobiernos de la institución educativa. Pero, además con una participación activa no solo en la dirección de la universidad sino también en la orientación de la enseñanza. Petición que no es nueva en el territorio colombiano dado que desde el período colonial en 1791 los estudiantes reivindicaban la enseñanza de las ciencias experimentales. Pero, ahora en 1909 exigían el participar no solo en esta orientación sino también como profesores adjuntos.

Con respecto a la educación laica, que los estudiantes colombianos reivindicaron en el primer congreso de 1910, no se evidencia como tema central en el segundo congreso de 1924 pero sí se expresa en el manifiesto de Córdoba cuando se critica la opresión clerical.

Aunque nos ocupamos preferentemente de los dos congresos, consideramos sin embargo relevante hacer mención al mensaje enviado a los miembros de la misión pedagógica alemana ${ }^{72}$ en el mismo año del segundo congreso de estudiantes colombianos. En este documento, modelo de esfuerzo y perspicacia, Germán Arciniegas se propuso recoger la más completa información sobre el estado de las Universidades Seccionales y presentarlas a los comisionados, estableciendo una radiografía del estado actual de la educación. Al respecto indica: "[...] libres de todo control, ajenas a toda corriente nueva de pensamiento, sin material de enseñanza, sin laboratorios, sin bibliotecas, sin gabinetes, sin orien-

\footnotetext{
69 Manifiesto de Córdoba Argentina, 1918. Publicado en Revista Historia de la Educación Latinoamericana. No. 11, (2008), 249.

70 Op, cit, 252.

71 Óp, cit., 254.

72 Dardo Cúneo. Óp. cit. 57-66. Se terminó de imprimir el día 30 de agosto de 1988 (Caracas Venezuela en los Talleres Cromotip. C.A. Calle del Loro, Urbanización Central, Quinta Crespo).
} 
taciones, sin profesorado y casi sin estudiantes, en las cuales se pierden valiosos esfuerzos, muy dignos de mejor suerte ${ }^{73}$.

En efecto, dentro de este contexto educativo analiza a la Universidad Nacional y concluye que "[...] no hallan campo en ella las ciencias sociales ni la preocupación filosófica, y todo allí se reduce a lo que pueda servir de auxilio a un profesional cuyas miras no vayan más allá de la botica o del escritorio abogadil" (p. 58). Pero, además reseña que no existe autonomía para nombrar a los profesores. Respecto a la influencia social, que debe ejercer la Universidad, es lamentable comprobar que se carece de una corriente ideológica que vincule el alma mater con todas las esferas del pensamiento y del saber y por ello propuso buscar un modelo de Universidad independiente, que dignifique el trabajo, mantenga y promueva una tendencia eminentemente social, mejor gobernada y un radio de acción más efectivo.

Por ello su aspiración se cifró en construir una Universidad nueva en su fondo y en su forma, que funcionara como un organismo dinámico, abierto a todos los requerimientos del saber, útil a la comunidad y que pudiera satisfacer las aspiraciones sociales de la Nación.

$\mathrm{Al}$ año siguiente del segundo congreso, destacamos la carta de Arciniegas a los estudiantes del gimnasio moderno, sustentada en lo que consideraría el fracaso de la Misión Pedagógica de técnicos alemanes, convocada por el gobierno de Pedro Nel Ospina, por no diseñar la Universidad Independiente, modelo de trabajo y de tendencia social que reclamaba el estudiantado. Por ello conviene advertir que en esta carta, desnuda de toda pretensión, Arciniegas invita a los alumnos del Gimnasio Moderno a hacer un plan completo de acción universitaria, lo que implica que en ese establecimiento educativo, creado por iniciativa de Agustín Nieto Caballero, se insinuaron programas de educación superior, encaminados a trabajar por la cultura, a crear una atmósfera favorable para la investigación científica y a abrir las puertas a las ideas de los pensadores europeos, de los cuales en la Universidad Oficial casi siempre se daba una versión tergiversada y caprichosa.

En esta misiva, Arciniegas denunció que a la Misión Pedagógica de los técnicos alemanes contratada por el Gobierno, se le envió un minucioso documento bien estructurado, que los técnicos no tuvieron en cuenta, por lo cual enfatizó que debía ser la juventud la que efectuara la reforma universitaria con sus propias manos y con sus propios medios, para que los hechos correspondiesen al vuelo generoso de su espíritu.

Por otra parte, Arciniegas destaca el espíritu de la raza e invoca posibilidades de cambio porque "[...] a los hombres de América nos une un impulso desconocido antes, lleno de matices que no puede apreciar el europeo de hoy y que darán en lo futuro la clave de una humanidad distinta en donde palpiten atributos de una grandeza que confundirá a los arios de oscuros nacionalismos. Ni las más desinteresadas teorías de occidente encajan dentro de nuestro modo,

73 En Reforma Universitaria 1918-1930, (1924), 57. 
dentro de la nobleza que nos pertenece por haber nacido en nuestro solar inculto pero marcada con el signo de augurios famosos". Y advierte con nostalgia que como "[...] la ley de la Reforma será redactada por un concilio de tudescos y cundinamarqueses" concluye "[...] yo creo que dentro de las repúblicas cabe otra república y esa república debe ser la Universidad, que oriente por caminos de civilización y de sabiduría, de lucha desinteresada y de esfuerzo fecundo".

Agustín Nieto Caballero, fundador del Gimnasio Moderno, fue un gran receptor y practicante de los criterios expuestos en el Manifiesto de Córdoba, sin embargo, solo los aplicó como programa de educación media en el sistema que introdujo bajo la denominada Escuela Nueva. En sus ensayos, y a diferencia de Germán Arciniegas, dejó su expresa constancia en cuanto a que "escuela y política se excluyen", por lo tanto, atribuyó al maestro la dignidad del sacerdote, con el encargo de modelar al ciudadano inculcándole los sentimientos de la veracidad, hombría, lealtad y caballerosidad, pero lejos de la política. En su estudio "La Escuela y la Vida" consigna esta acerba crítica sobre los catedráticos que presumen de sabios. Al respecto considera "Contrariamente a lo que creen muchos pedagogos, los estudiantes piensan que aquellos catedráticos que hacen ostentación de su sabiduría son una verdadera calamidad. Les dan una montaña de conocimientos, es cierto, pero con cuánto tedio se les escucha: es ya lugar común decir que no es lo mismo saber, que saber enseñar, y no es, efectivamente, el hombre erudito el que mejor enseña, sino el que, sabiendo alguna cosa, conoce el camino que va al espíritu y al corazón del alumno, y posee el arte de transmitir lo que él sabe, de poner ánimo en lo que dice, de encariñar al discípulo con la materia que dicta"74.

Hay que destacar a Luis López de Mesa ${ }^{75}$, que como hemos indicado fue uno de los líderes del primer congreso de estudiantes y para 1917 fue elegido Concejal de Bogotá, y luego Diputado a la Asamblea Departamental y Representante a la Cámara de Representantes. En cuanto a su actividad pedagógica (1912-1916) se desempeñó como profesor de Historia de la Medicina, de Sociología americana y de estética e historia del arte en la Universidad Nacional de Colombia. El hilo conductor de gran parte de su elaboración teórica fue el concepto de educación que, junto con la raza y el mejoramiento de esta, la economía y la 'voluntad

74 Nieto Caballero, Agustín. "La Escuela y la Vida”, citado en Universidad Utopía, ICFES, Editora Nacional de Colombia Ltda., 1994, 307.

75 Luis López de Mesa. Médico, educador, filósofo y científico. Nació el 12 octubre de 1884 en Don Matías (Antioquia) y falleció el 18 de octubre de 1967. Hijo de Bartolomé López de Mesa y Virginia Gómez de ascendencia española e inglesa. Se graduó de bachiller Colegio de San Ignacio (Medellín). Estudió Medicina en la Universidad Nacional de Colombia en 1912. Se Especializó en Psiquiatría y Psicología en la Universidad de Harvard, en 1916. Perteneció a la Generación del Centenario. Participó en los debates sobre la raza y la educación en los años de 1920. Considero que eran necesarias la enseñanza femenina y la educación física. Buscando la integración del campo (rural) con la Ciudad (lo urbano) creó la Comisión de Cultura Aldeana-CCA. Su programa se inspiró en las Misiones Pedagógicas mejicanas creadas en 1923, por José Vasconcelos (escritor y político mejicano, nació en Oaxaca 1882-1959) publicó libros de carácter sociológico, filosófico y crítico, así como en las misiones pedagógicas organizadas durante la república española. Consideraba que uno de los problemas cruciales de Colombia era la fosa que separaba el campo de la Ciudad. Para remediar lo anterior, trató de acometer una fuerte campaña educativa. Escribió algunos ensayos filosóficos, apartándose de la tradición tomista. Su obra se caracteriza por un cientificismo rudimentario como elemento primario de la reflexión filosófica. Revista: Orientación filosófica Latinoamericana. La Revista Universidad de Bogotá". Octubre de 1928. Publicada en "el Gráfico" encuesta. "Suplica a usted le expresa en pocas palabras ¿Cuál es el principio filosófico que mayor influencia ejerce en su espíritu? Firmado: Germán Arciniegas y Luis López de Mesa. 
creadora', considerada como factores de desarrollo. De todas maneras, estas concepciones racistas y el carácter contradictorio a los ideales liberales se hacen patentes de nuevo en 1949, al señalar en un artículo de la revista bogotana "Cultura" que el mestizaje en Colombia estaba trastocando los 'valores supremos' y al exponer en el mismo texto los peligros políticos de la alfabetización popular. Este representante de la generación del centenario, participó en el gobierno del Presidente Eduardo Santos, donde las teorías racistas de López de Mesa lo llevaron a emitir una circular prohibiendo a las Embajadas de Colombia que visaran judíos para venir al país. Posteriormente, fue nombrado Ministro de educación ${ }^{76}$, durante el gobierno de Alfonso López Pumarejo (1934-1938) y renunció por una huelga estudiantil.

En ese entonces fue defensor de las teorías de Bentham y consideraba que en la universidad, "cada profesor debe doctrinar a sus discípulos, con su buen ejemplo, primero que todo, con hábiles instrucciones, luego, cada vez que la oportunidad así lo indique" 77 . En cuanto a la misión educativa de la universidad, la establecía en relación con el ciudadano y señalaba que "tal misión se cumple a través de múltiples facultades que informan su claustro, donde se preparan técnica y éticamente los alumnos de profesiones libres que más directamente habrán de dirigir las funciones del Estado, la cultura social y la economía de la nación de estas instituciones, dos son eminentísimas: la de médicos y la de jurisconsultos, como que una y otra defienden la vida, el honor y los haberes de sus conciudadanos, que una y otra proveen a la rectoría de la vida social y la república; que una y otra, en fin, abastionan con su ejemplo la tarea espiritual de su pueblo y la conducen" 78 .

Luis López de Mesa se destaca por la creación de la campaña de cultura aldeana y rurall ${ }^{79}$, en su periodo de Ministro de educación y por haber reorganizado este ministerio en cinco secciones a saber: 1 . dirección de Universidades e Institutos de Alta Cultura; 2. dirección de Normales e Institutos pedagógicos de educación primaria; 3. dirección de bachillerato y educación femenina; 4. dirección de Bellas artes, bibliotecas y monumentos públicos y reliquias prehistóricas y 5 . dirección

76 Luis López de Mesa, nombrado Ministro de Educación Nacional por Decreto 1618 de 1934 (agosto 13) "Nombrar al señor doctor Luis López de Meza Ministro de Educación Nacional” artículo único. Alfonso López Pumarejo, Presidente de la República, Tomado Diario Oficial Año LXX. Número 22671. Miércoles 29 de noviembre de 1934, 553. del 13 de agosto de 1934 al 24 de septiembre de 1935. Le sucedió el señor doctor Darío Echandía Olaya, nombrado por Decreto 1805 de 1935 (octubre 7) "Nombrase Ministro de Instrucción Pública al señor doctor Darío Echandía Olaya” artículo único. Firmado Alfonso López Pumarejo, Presidente de la República. Tomado: Diario Oficial Año LXXI número 230|10 del miércoles 16 de octubre de 1935, 97.

77 Luis López de Mesa (1995) Función Deontológica de la universidad. Pensamiento Pedagógico de los grandes educadores de los países del Convenio Andrés Bello. Antología. Bolivia, Colombia, Chile, Ecuador, Panamá, Venezuela. Tomo I Convenio Andrés Bello-CAB. Secretaria Ejecutiva. Área de Educación. Santafé de Bogotá. Colombia. Pedro Henríquez Guajardo Secretaria Ejecutiva. Hernando Bernal Valenzuela, Secretario de Administración y Finanzas. Edición especial efectuada por Editorial Voluntad S.A. para el Convenio Andrés Bello según Contrato. Estudios nacionales Mariela Salgado, 279-282.

78 Luis López de Meza (1995), 281.

79 Ley 12 de 1934 (diciembre 01) "Por la cual se reorganiza el Ministerio de Educación Nacional y se dictan otras disposiciones". Presidente del Senado Federico A. Gómez. Presidente de la Cámara de Representantes E. López Pumarejo. Secretario del Senado Fidel Perilla Barreto. Secretario de la Cámara de Representantes Carlos Samper Sordo. Presidente de la República Alfonso López Pumarejo. Ministro de Educación Nacional Luis López de Mesa. Diario Oficial número 22765 del 20 de diciembre de 1934. 
de Educación física. Secretaría de la Comisión de Cultura Aldeana y Rural" art. 1 o 80 .

En definita, queda claro que el movimiento estudiantil colombiano y el de Córdoba abogan por la universidad libre donde los estudiantes tienen la palabra en la administración y la enseñanza. Y, en efecto, este es el hilo conductor que une a las dos generaciones en Colombia: la del centenario y la de los nuevos. Es importante, sin embargo, mencionar que estos líderes estudiantiles colombianos cuando ocuparon los cargos de ministros de educación no plasmaron estos sueños e ideales de su juventud. Quizá, la pregunta que queda en la palestra es la referente al hecho de cuándo llegaron al ministerio de educación ${ }^{81}$, Agustín Nieto Caballero, Luis López de Mesa, Germán Arciniegas, ¿qué pasó con la autonomía universitaria? Todos obtienen el ministerio después de un recorrido como dirigentes estudiantiles con una producción académica sobre la universidad, fueron creadores de instituciones educativas y científicas y poseían un amplio conocimiento de la educación y la universidad en contextos internacionales. El primero de ellos fue Director de Educación en 1923 y Ministro de Educación en 1936. El segundo, López de Mesa, se desempeñó en el gobierno de Alfonso López Pumarejo como Ministro de educación ${ }^{82}$ y desarrolló el programa de la revolución en marcha y él, personalmente, llevó a cabo la campaña de la "Cultura aldeana", cuando Bogotá tenía 300 mil habitantes. El tercero, Arciniegas, participó como Ministro de Educación en los gobiernos de Eduardo Santos y Alberto Lleras Camargo ${ }^{83}$. Además, no deja de sorprender que dentro de sus ideales políticos de avanzada no hubo espacio para la participación femenina en la vida política universitaria.

\section{CONCLUSIÓN}

Esta investigación aporta nuevos elementos para la historiografía del movimiento estudiantil colombiano en el período de 1910 a 1924, porque se ocupa de recoger los contextos políticos precedentes a la ruptura ideológica de los dos partidos en cuanto a la visión de la iglesia y de la religión católica en la educación, particularmente sobre la universidad. Se clarifica que en medio de una hegemonía conservadora surge un grupo de intelectuales, la del centenario, que organizan el primer congreso nacional de estudiantes en 1910 y bajo los ideales liberales, y del positivismo del siglo XIX, se presentan en la política nacional con planteamientos de una universidad libre y autónoma.

80 Ley 12 de 1934 (diciembre 01) "Por la cual se reorganiza el Ministerio de Educación Nacional y se dictan otras disposiciones". Presidente del Senado Federico A. Gómez. Presidente de la Cámara de Representantes E. López Pumarejo. Secretario del Senado Fidel Perilla Barreto. Secretario de la Cámara de Representantes Carlos Samper Sordo. Presidente de la República Alfonso López Pumarejo. Ministro de Educación Nacional Luis López de Mesa. Diario Oficial número 22765 del 20 de diciembre de 1934.

81 Este Ministerio fue creado en 1927.

8213 de agosto $d 1934$ a 10 de julio de 1935.

83 De 1941 a 1942 con Eduardo Santos y Funda el Instituto Caro y Cuervo. Regresa de 1942 a 1945 Luego con el Gobierno de Alberto Lleras de 1945 a 1946. 
Por otra parte, la generación de los nuevos, que se une a la del centenario con publicaciones periodísticas, y desde la política liberal y socialista, sueñan una universidad libre y autónoma. Desde esos ideales, la organización estudiantil se une a la Federación de estudiantes colombianos. A esta última se le debe reconocer su sentido de pertenencia e identidad con los estudiantes latinoamericanos. Desde esta perspectiva, se establece un mismo lenguaje evidenciado en los manifiestos de: libertad, autonomía, unidad latinoamericana, enseñanza de la ciencia, liderazgo estudiantil. No obstante, se debe clarificar que los estudiantes universitarios pertenecían a una élite muy selecta, la única que podía ingresar a estos claustros educativos.

Nos preguntamos por el recorrido político de los líderes de estos dos movimientos ¿dónde quedó la bandera de la autonomía universitaria?, ¿en qué momento la abandonaron?, ¿Por qué no defendieron los mismos ideales cuando llegaron a los altos cargos del Ministerio de Educación en Colombia? Por otra parte, resulta paradójico que en la calidad de líderes estudiantiles con posiciones políticas de avanzada hayan excluido a la mujer en estas organizaciones y movimientos universitarios colombianos de la época. Fue, en efecto, hasta la Constitución de 1991, que Colombia asume legalmente la autonomía universitaria. Aunque, en la realidad sea muy cuestionable la forma de designación y elección de los miembros de los consejos superiores de estas máximas instituciones educativas, el verdadero nudo gordiano, de llevar a la práctica la autonomía universitaria, sigue sin solución porque la administración se impone sobre la academia y las voces de los estudiantes y profesores continúan sin una participación real en la dirección universitaria.

En la época presente cuando se entrelazan instituciones e ideologías y todo se concibe bajo el modelo de empresa preindustrial y capitalista, la universidad enfrenta nuevos desafíos que la han reducido a institución marginal con pérdida ostensible de sus atributos. En el caso colombiano, la universidad es asfixiada por el gobierno y es liquidada poco a poco por las restricciones financieras obligatorias que, en consecuencia, limitan el ingreso a la educación superior a la gran mayoría de la población colombiana.

Concluimos, que estos planteamientos abren un nuevo campo de análisis en torno a la prospectiva funcional de la universidad contemporánea y sugerimos oportuno y necesario que se abra el debate sobre aquellos aspectos no previstos en el Manifiesto de Córdoba de 1918, para lo cual encontramos un gran estímulo en las conclusiones del estudio sobre el tema de la Universidad Latinoamérica y del Caribe en los desafíos del siglo XXI, "pensada y reformada desde los años 60 bajo lineamientos, primero de Estados Unidos y luego por organismos internacionales que trazan directrices donde la globalización imprime un sello de mercado desapareciendo las humanidades y priorizando lo tecnológico" ${ }^{84}$. En definitiva, a cien años del movimiento estudiantil de Córdoba, la autonomía universitaria tiene aún un largo camino por recorrer y los desafíos del futuro de la universidad del Estado se encuentran en la incertidumbre de la supervivencia por la asfixia presupuestal. El Estado parece que olvidará, que esta institución, es la que lidera la formación de las nuevas generaciones y que debe cumplir con la misión social y científica que le corresponde en el siglo XXI.

84 Diana Elvira Soto Arango y Aracely Forero "La Universalidad Latinoamérica y del Caribe en los desafíos del siglo XXI. Revista Historia de la Educación Latinoamericana. Vol. 18 No. 26, (2016): 304. 


\section{FUENTES}

Constitución de 1886.

Concordato de 1887.

Consejo Nacional Constituyente. Constitución Política de la República de Colombia. Secretaría de Instrumentación pública Enrique Álvarez. D.O. Año XXII. Bogotá, sábado 07 de agosto de 1886. No. 6758-6759. pp. 801-807.

Decreto 595 de 1886 del 9 octubre "Por el cual organiza la instrucción pública primaria" D.O No. 6844-6845.

Decreto 596 de 1886 del 9 octubre "Sobre instrucción pública secundaria y profesional". D.O. No. 6831 del 17 de octubre de 1886.

Reforma Educativa de 1870.

Reforma Universitaria 1918-1930, 1924.

Revista La Universidad 1921.

Manifiesto de Córdoba Argentina, 1918. Publicado en Revista Historia de la Educación Latinoamericana. No. 11, (2008), 249.

Ministerio de Educación Nacional. Educación Colombiana. Disposiciones orgánicas y reglamentarias de la Educación Nacional en las ramas de Primaria, Normalista Superior y Bachillerato, y otros aspectos de interés general 1903 - 1958. Bogotá: Imprenta Nacional. 1959.

Ministerio de Educación Nacional. La educación colombiana, 1903 - 1958. Tomo I. Compilación Legislativa. Bogotá: Imprenta Nacional. 1959.

Ley 39 de 1903. Ley Orgánica de Instrucción Pública. Diario Oficial Número 11931. Bogotá, viernes 30 de octubre de 1903.

\section{REFERENCIAS}

Alvarado, María Lourdes “El movimiento estudiantil de 1875. Entre las demandas académicas y los intereses políticos", en Movimientos estudiantiles en América y Europa. Tomo II, Córdoba, Argentina.

Álvaro Acevedo. Memorias de una época. El movimiento estudiantil en Colombia en los años sesenta y setenta del siglo XX. Bucaramanga, Universidad Industrial de Santander, 2016.

Acevedo Tarazona, Álvaro, 1968. Historia de un acontecimiento: Utopía y revolución en la universidad colombiana. Bucaramanga, Publicaciones UIS, 2017.

Cúneo, Dardo. La Reforma Universitaria 1918-1930. Compilación, prólogo, notas y cronología. Biblioteca Ayacucho. Caracas Venezuela, 1988. No. 39. Colombia 1924. Mensaje de la juventud a los Miembros de la Misión Pedagógica. Segundo Congreso Nacional de Estudiantes.

Henao, Jesús María, y Arrubla, Gerardo. Historia de Colombia para la enseñanza secundaria. Librería Colombiana, C. Roldán \& Tamayo, 1952.

Jodele, Deniset, "El movimiento de retorno al sujeto y el enfoque de las representaciones sociales", Revista Cultura y Representaciones Sociales. Vol., 3, No. 5 (2008): 32-63.

Jodele,Deniset, "La representación social: fenómenos, concepto y teoría Psicología Social II. Pensamiento y vida social. Psicología social y problemas sociales", compilado Moscovici, S. (comp.). Barcelona, Ediciones Paidós.

Lebot, Ivon. Elementos para la historia de la educación en Colombia en el siglo XX, en Boletín Mensual de Estadística Nº 249 DANE, Bogotá: 1975.

Marsiske Schulte. Renate Johanna “Clases medias, universidades y movimientos estudiantiles en América Latina 1900 - 1930". En Movimientos Estudiantiles En La Historia de América Latina. Editado por Universidad Nacional Autónoma de México. México: Universidad Nacional Autónoma de México, 1999.

Melo, Jorge Orlando. La evolución económica de Colombia 1830-1900. Bogotá: Manual de Historia de Colombia, tomo II, Instituto Colombiano de Cultura, 1979.

Monroy, Armando Suescún. "Datos para un balance de la universidad colombiana en el siglo XX" En Movimientos universitarios en América Latina, editado por Olmedo Vargas Hernández: 
Tunja: Doctorado en Educación, UPTC, RUDECOLOMBIA, 2005.

Navarro, Pedro Juan. Constitución política de la República de Colombia, 1936. Historia, proceso, comentarios.

Nieto Caballero, Agustín. Sobre el problema de la educación nacional. Bogotá: Ministerio de Educación Nacional, Ciencia y Cultura, 1937.

RivadeneiraVargas, Antonio José. El Poder del Saber y los Arquetipos de la Universidad Colombiana, Bogota: Academia Colombiana de Historia, 2002.

Ospina Vásquez Luis. Industria y protección en Colombia, 1810-1930 Bogotá: la oveja negra, 1955.

Peña Consuegra, Eduardo, Origen y desarrollo de la burguesía colombiana. Barranquilla: Tipografía Dovel, 1971.

Ricoeur, Paul, Ideología y utopía. Editorial Gedisa. Barcelona, 1994.

Silva Olarte, Renán. La educación en Colombia 1880- 1930. Tomo IV Educación y Ciencia. Luchas de la mujer, vida diaria. Nueva Historia de Colombia-NHC. Director Científico y Académico Álvaro Mejía. Asesores Jorge Orlando Melo y Jesús Antonio Bejarano. (Planeta Colombiana Editorial, 1989), 84.

Soto Arango, Diana Elvira. Polémicas universitarias en Santa Fe de Bogotá. Siglo XVIII. Bogotá: Universidad Pedagógica Nacional, 1993.

Soto Arango, Diana Elvira. "El movimiento de estudiantes y catedráticos en Santa Fe de Bogotá afines del siglo XVIII." En Movimientos estudiantiles en la historia de América Latina, editado por Renate Marsiske. México: Universidad Nacional de México, Plaza y Valdés Editores, 1999.

Soto Arango, Diana Elvira. "Aproximación histórica a la Universidad Colombiana", en Revista Historia de la Educación Latinoamericana. No. 7 (2005): 99 - 136.

Soto Arango, Diana y Lafuente, María Isabel. Autonomía y modelos universitarios en América Latina. Tomo II Bogotá, León. Universidad de León, España, Asociación Colombiana de Universidades. ASCUN. Universidad Pedagógica y Tecnológica de Colombia, RUDECOLOMBIA, 2007.

Soto Arango, Diana Elvira. La Universidad en el periodo Colonial, (Tunja: UPTC, 2011).

Soto Arango, Diana Elvira. "La Universidad Colombiana. Políticas públicas y reformas educativas 1774-2012", en Historia de la Universidad Latinoamericana, Editora María Cristina Vera, Colección Historia y Prospectiva de la Universidad Latinoamericana, Tomo V, (Córdoba, Universidad de Córdoba, Argentina, 2013). 313-368.

Soto Arango, Diana. "Periodos de reforma universitaria en Colombia de la colonia al siglo XXI", Revista Historia de la Educación Latinoamericana 16, No. 22, Vol. 16. (2014): 277-337.

Soto Arango, Diana y Forero, Aracely “La Universalidad Latinoamérica y del Caribe en los desafíos del siglo XXI. Revista Historia de la Educación Latinoamericana. Vol. 18 No. 26, (2016): 304.

Suescún Monroy, Armando. "Datos para un balance de la universidad colombiana en el siglo XX", en Movimientos universitarios en América Latina, ed. Olmedo Vargas Hernández, Tunja: Doctorado en Educación, UPTC, RUDECOLOMBIA, 2005.

Vásquez, Luis Ospina. Industria y protección en Colombia, 1810-1930. Bogotá: 1955.

Vera, María Cristina. “Un precedente de la reforma del 18: el I Congreso Internacional de estudiantes americanos. Montevideo 1908". En Movimientos estudiantiles en América y Europa, Tomo II, editado por María Cristina Vera, Córdoba, Editorial, 2006, 89,90.

Soto Arango, Diana Elvira; Rivadeneira, José Antonio; Duarte Acero, Jorge Enrique; Bernal Villate; Sandra Liliana. "La generación del movimiento estudiantil en Colombia. 1910-1924"

Revista Historia de la Educación Latinoamericana. Vol. 20 No. 30 (2018): 217-241. 